The need for training more oceanographers was emphasized, and it was decided that the universities should be asked to help by teaching oceanography and doing all they can to encourage postgraduate research in marine physics as well as marine biology.

The Conference endorsed the programme of the National Institute of Oceanography, and considered that its attempt to concentrate on the basic problems, which will benefit the Commonwealth countries by helping them to solve their local problems, should be supported as fully as possible.

The First Lord of the Admiralty, the Right Hon. J. P. L. Thomas, and the Civil Lord, Mr. Simon Wingfield Digby, chairman of the National Oceanographic Council, did much to encourage the work of the Conference. They were hosts at a reception to all members after the first day's session and at $a_{0}$ dinner, at which the First Lord presided, given in honour of the Commonwealth representatives, at the close of the meetings.

\section{NEW FORMS OF THERMIONIC CATHODE}

A

COLLOQUIUM on new forms of thermionic cathode, sponsored by the Institute of Physics and the Physical Society, was held on October 21 at Hirst Hall on the estate at Wembley of the General Electric Company, Ltd., An introductory survey was given by D. A. Wright (G.E.C., Wembley), who pointed out that, for continuous operation for many thousands of hours, none of the established cathodes (Nos. 1, 3 and 9 in Table 1) can be relied upon to give more than 1-2 amp. $/ \mathrm{cm}^{2}$. The oxide cathode will give some tens of amp. $/ \mathrm{cm}^{2}$ in short pulses, but is limited for continuous high current by its sensitiveness to imperfect vacuum, by the dielectric properties of the coating and by evaporation and electrolysis of coating material. Thus, to improve the performance, a cathode with metallic properties is desirable, with a low rate of loss of emissive material. The lowest-temperature emitter obtainable without a dielectric coating appears to be that which maintains a monatomic layer of barium on a metal surface, possibly with some oxygen present. The work function of such a cathode is $1 \cdot 6-2 \cdot 0 \mathrm{eV}$., so that it must be operated at $950^{\circ} \mathrm{C}$. or more. At these temperatures, surface barium is rapidly lost by evaporation, and must be replaced from a reservoir in the cathode. The next four papers at the colloquium described cathodes of this type.

Dr. A. Venema (Philips, Eindhoven) described the three forms of Philips dispenser cathode. In the original $L$ cathode (No. 5 in Table 1 ) the reservoir is of barium-strontium carbonate, which decomposes to oxide during pumping and is placed beneath a plug of porous tungsten. The work of Rittner has clarified the mechanism of these cathodes, indicating that barium is formed following reduction of the oxide by the tungsten, and diffuses through the pores as vapour by Knudsen flow. A complete covering of barium on tungsten is maintained by diffusion over the outer surface of the tungsten particles. The life, as shown in the table, exceeds eight thousand hours at a brightness temperature of $950^{\circ} \mathrm{C}$., at which the saturated emission is $1.3 \mathrm{amp} . / \mathrm{cm} .{ }^{2}$. The life is determined by evaporation, and decreases by a factor of $2 \frac{1}{2}$ per $50 \mathrm{deg}$. C. rise of temperature. The impregnated cathode has similar properties, and is formed by heating a porous tungsten plug in contact with barium aluminate at $1,750^{\circ} \mathrm{C}$. in vacuum. The aluminate penetrates the pores, and in operation is reduced by the tungsten. A third type of cathode is being developed, in which tungsten powder and barium aluminate are mixed in powder form, pressed and sintered, again at $1,700-1,800^{\circ} \mathrm{C}$.

In discussing the chemical reactions which can be utilized to supply barium to a tungsten surface, Dr. H. Huber (C.S.F., Paris) said that the compounds barium aluminate, silicate, titanate, thorate and tungstate have been considered. The work of Eisenstein, John and Affleck has shown what reducing agents are appropriate for each compound, and Dr. Huber described the results of his study of the emission of cathodes formed by mixing the powdered oxide, tungsten and a suitable reducing agent, pressing and heating at $1,300^{\circ} \mathrm{C}$. The preferred cathode is ' 103 ' (No. 6 in Table 1), containing five molecular parts of barium tungstate $\left(\mathrm{Ba}_{3} \mathrm{WO}_{6}\right)$, fifteen molecular parts of aluminium powder and eighty of tungsten powder, though similar results are obtained if the aluminium is replaced by tungsten carbide, and molybdenum can replace the tungsten powder. Presintering at $1,500^{\circ} \mathrm{C}$. is found to be necessary to give long life.

It is not possible to form a cathode by mixing barium/strontium carbonate with tungsten, as there is a reaction which prevents subsequent reduction of the oxide to free barium. The carbonate can, however, be mixed with a more inert metal containing a little reducing agent. Dr. J. M. Dodds (Metropolitan-

Table 1

\begin{tabular}{|c|c|c|c|c|c|c|}
\hline Type & $\begin{array}{l}\text { Operating } \\
\text { temperature }\end{array}$ & $\begin{array}{l}\text { Radiated power } \\
\text { (watts } / \mathrm{cm}^{2} \text { ) }\end{array}$ & $\begin{array}{l}\text { Maximum usable } \\
\text { d.c. emission } \\
\text { (amp./cm. }{ }^{2} \text { ) }\end{array}$ & Life ${ }^{(h r}$.) & $\begin{array}{l}\text { Work function } \\
(\mathrm{eV} .)\end{array}$ & $\begin{array}{c}\text { Richardson } \\
\text { A value }\end{array}$ \\
\hline $\begin{array}{l}\text { (1) Tungsten } \\
\text { (2) Tantalum } \\
\text { (3) Thoriated tungsten } \\
\text { (4) Lanthanum boride } \\
\text { (5) Philips dispenser } \\
\text { (6) Huber } 103 \text { (barium- } \\
\text { tungsten) } \\
\text { (7) Dodds (barium-nickel) } \\
\text { (8) Beck (barium-nickel) } \\
\text { (9) Oxide cathode }\end{array}$ & $\begin{array}{l}2,600^{\circ} \mathrm{K} . \\
2,400^{\circ} \mathrm{K} . \\
2,000^{\circ} \mathrm{K} . \\
1,680^{\circ} \mathrm{K} . \\
950^{\circ} \mathrm{C} . \mathrm{B} . \mp \\
1,050^{\circ} \mathrm{C} . \mathrm{B} . \\
1,200^{\circ} \mathrm{C} . \mathrm{B} . \\
950^{\circ} \mathrm{C.B} . \\
1,340^{\circ} \mathrm{K} . \\
1,270^{\circ} \mathrm{K} . \\
1,100^{\circ} \mathrm{K} . \\
1,200^{\circ} \mathrm{K} .\end{array}$ & $\begin{array}{l}80 \\
55 \\
25 \\
40 \\
4^{*} \\
\\
6^{*} \\
8^{*} \\
3 \cdot 3^{*} \\
3 \cdot 7^{*} \\
3 \cdot 0^{*} \\
2 \cdot 8 \\
4 \cdot 2\end{array}$ & $\begin{array}{l}1 \cdot 0 \\
4-5 \\
6 \\
3 \\
1 \cdot 5 \\
0 \cdot 5 \\
1 \cdot 0\end{array}$ & $\begin{array}{r}10,000 \\
10,000 \\
5,000 \\
>250 \\
8,000 \\
\left.\begin{array}{r}4,000 \\
\sim 400\end{array}\right\} \\
\left.\begin{array}{r}3,000 \\
9,000\end{array}\right\} \\
\left.\begin{array}{r}3,000 \\
<1,000\end{array}\right\}\end{array}$ & 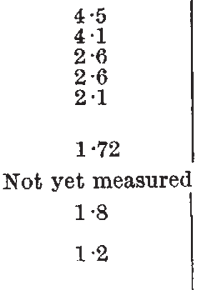 & $\begin{array}{r}60 \\
37 \\
3 \\
25 \\
100 \\
\\
3\end{array}$ \\
\hline
\end{tabular}

- These figures assume thermal emissivities for Nos.

(that is, $0 \cdot 2$ ). In practice they are likely to be higher.

+ The figures quoted for life are rough indications only, in all cases.

$\ddagger$ Temperatures in ${ }^{\circ} \mathrm{K}$. are true temperatures. Temperatures in ${ }^{\circ} \mathrm{C} . \mathrm{B}$. are pyrometer brightness temperatures 
Vickers) and A. H. Beck (Standard Telecommunications Laboratories, Ltd.) described cathodes of this type, formed by mixing $30-40$ parts by weight of carbonate with $70-60$ parts of nickel powder, pressing and sintering. Dr. Dodds adds as reducing agent $0 \cdot 1$ per cent silicon, and presses at 10 tons/in. ${ }^{2}$. Mr. Beck uses 1 per cent zirconium hydride as reducing agent, and presses at 80 tons/in. ${ }^{2}$. His study of the work function has indicated that the activated cathode is nickel with 70 per cent of the surface covered with barium. The temperature coefficient of the work function is $1.4 \times 10^{-4}$ eV./deg. C.

C. P. Lea-Wilson (Services Electronics Research Laboratory, Harlow) described a high-temperature magnetron cathode which emits from thorium-ontungsten. This again is formed by pressing and sintering, but employs either thorium oxide or thorium metal (about 2 per cent) mixed with tungsten carbide and tungsten. With thoria, gas is liberated over a long period of operation, and about 10 per cent of carbide is necessary to obtain emission. The thorium gives rapid outgassing and activation, and is to be preferred. In the discussion, Mr. Lea-Wilson said that the carbide is desirable even when thorium is used, possibly because it minimizes surface oxidation. There is no information as to whether thorium carbide is formed. The cathode gives a pulsed emission of 20 amp. $/ \mathrm{cm}^{2}$ at about $1,700^{\circ}$ C., and a number of valves have been operated satisfactorily for more than a thousand hours.

Another high-temperature cathode using lanthanum boride as the emitter was described by B. N. Watts (British Thomson-Houston Co., Ltd., Rugby). This is formed by reaction of metal and boron in hydrogen at $1,400^{\circ} \mathrm{C}$., and is either painted and sintered on a tantalum filament, or pressed, sintered, machined and heated indirectly. It is activated at $1,600^{\circ} \mathrm{C}$. and gives 1 amp. $/ \mathrm{cm}^{2}$ at $1,400^{\circ}$ C., the d.c. and pulsed emission being equal. No long-life test information is yet available.

Finally, P. O. Hawkins (Services Electronics Research Laboratory, Baldock) described an oxide cathode in which the normal disadvantages are overcome by applying the coating on the inner surface of a hollow box, and extracting the electrons through a small hole. From a hole $\frac{1}{3} \mathrm{~mm}$. diameter, spaced $2 \mathrm{~mm}$. from the anode, the current is very small below $920^{\circ} \mathrm{C}$. At high temperatures the current, increases at first rapidly with voltage, and then linearly and less rapidly. It exceeded 50 m.amp. at, an anode voltage of $5 \mathrm{kV}$. at $1,230^{\circ} \mathrm{C}$. This current if uniform over the hole would be $60 \mathrm{amp} . / \mathrm{cm} .{ }^{2}$; but, in fact, the beam is found to be hollow, and the current for varying hole size varies with the perimeter. The mechanism is not understood.

In discussion, Dr. D. Gabor suggested that Mr. Hawkins's cathode contains a plasma from which electrons emerge with high velocity, and the latter agreed that it does not appear to contain an electron gas at the cathode temperature. Dr. P. N. Daykin asked whether $n$ small holes would multiply the emission, and was told that this is so, giving an $n$-fold multiplication until the hole spacing becomes of the order of the hole diameter. M. E. Haine said that the beam current density per unit solid angle has a definite limit, so that a quotation of amp. $/ \mathrm{cm}^{2}$ can be misleading. In reply to a remark by Dr. O. Klemperer, Mr. Hawkins said that low-voltage measurements have not been made. Questioned about secondary emission, Mr. Watts said that the secondary-emission coefficient of lanthanum boride has not been measured. Mr. Beck said that his cathodes have a value 10 per cent higher than that for pure nickel, while Dr. Venema agreed that the value for the $L$ cathode is between $1 \cdot 0$ and $1 \cdot 5$. Dr. Huber discussed with Dr. Venema the reason for the former's failure to obtain good emission from bariumaluminate tungsten mixtures containing no additional reducing agent, and it appeared that the barium content and the sintering temperature are the important factors.

\section{BRITISH WEED CONTROL CONFERENCE, 1954}

$T$ HE second British Weed Control Conference was held at Harrogate during November 2-4 and was attended by four hundred delegates, including representatives from the British Colonies and most European countries. The Conference was organized on lines similar to those of the first one in 1953 ; that is, the emphasis was on the technology of weed control rather than on the underlying fundamental principles. The papers were divided into two broad classes, one concerned with general reviews of various aspects and the other with research reports on individual topics. The general papers again fell into two groups: the first related to the problems of commercial application, the efficiency of the available spraying equipment, the rotation of weed-killers, schemes for the approval of commercial products, and the legal aspects of spray damage; the second group contained surveys of modern developments in the use of herbicides and the associated problems of the dispersal of weed seeds and the role of mechanical cultivation.

Dr. W. G. 'Templeman (Jealott's Hill Research Station) reviewed the present position of herbicides in British agriculture. He pointed out that, although great advances have been made in the control of annual weeds in cereal crops, there still remain some relatively resistant and extremely important weeds, such as Avena fatua and Alopecurus agrestis, for which there are no adequate methods of control. $\mathrm{He}$ also emphasized that, while for many crops herbicidal applications are proving of great practical value, the position is far less satisfactory for root crops and many horticultural crops. In the past, too much stress has been laid on the total eradication of the weeds, and in many instances a better approach would be an endeavour to inhibit growth through the disorganization of the physiological processes. For example, 2,4,6-tribromophenylnitramine causes germinating seedlings to lose their capacity to react to tropic responses; but so far no compound with these characteristics has been discovered which is sufficiently selective.

While agreeing that herbicidal applications are playing an important part in British agricultural systems, Prof. H. G. Sanders (University of Reading) nevertheless felt that there is some danger that effective cultivation is not being fully appreciated. He was of the opinion that the hoe does more than kill the weeds and that its use in many circumstances is of direct benefit to the crop.

The organization of weed control investigations sponsored by the United States Department of 